\title{
Modernization of transport infrastructure for the development of pedestrian and bicycle paths on the example of a large city in Russia
}

\author{
Irina Kustysheva ${ }^{1, *}$ and Anastasia Konyukhova ${ }^{1}$ \\ ${ }^{1}$ Industrial University of Tyumen, 625001, Tyumen, Russia
}

\begin{abstract}
The article examines the promising directions of the existing concept of the Russian Federation on bicycle transport. Unlike Western countries, bicycle transport in Russia is only gaining its popularity and many people who preferred cars, in the spring-summer time, give their preference to bicycles and scooters. The study proves the relevance of the issue at stake, justifies the modernization of the existing transport frame of the territory and the need for its improvement with the help of a new project that will create comfortable conditions for movement and will be very significant for the city. The priority development of the territory is considered through the construction of a new pedestrian and bicycle transport bridge. The authors have developed proposals for solving the problem for comfortable movement of pedestrians and cyclists, as well as for people with limited mobility. The experience of foreign countries in creating projects of transport infrastructure for walking and cycling, which allows creating the most comfortable conditions for movement around the city, is generalized.
\end{abstract}

\section{Introduction}

Recently in Russia, bicycle paths have become widespread, although all over the world, this is a familiar form of transport. With the advancement of technology, the bicycle and other vehicles will be given new life in the coming years. Even now, electric bicycles allow you to easily move around the city, even with difficult terrain. Electric scooters are compact and maneuverable. Every year, new individual means of transportation around the city are invented, so it is difficult for me to imagine who we will meet on the bike paths in a few years. Perhaps they will soon lose the name of "bike paths", and will become lanes for individual low-speed (up to $25 \mathrm{~km} / \mathrm{h}$ ) transport.

There is a whole concept for the development of bicycle transport in Russia (2017)

The process of bicycle transport is becoming global. In European countries, this direction is supported, as it ensures the development of environmental awareness in Western society and, to a large extent, the choice of a vehicle caused by it. The government of each country proceeds from the fact that an adult citizen is responsible for the formation of his transport behavior.

\footnotetext{
* Corresponding author: irina1983kust@gmail.com
} 
Currently, in the most developed countries, the number of bicycles far exceeds the number of road transport, and the number of cycling trips is constantly increasing. In most developed countries, cycling is developing at a rate that exceeds the rate of development of road transport. For example, 4.5 million bicycles are sold annually in Germany. This growth is facilitated by its objective advantages, friendliness towards nature, the need for a relatively low investment, complemented by significant progress in the field of road construction of bicycle transport networks and bicycle transport structures, as well as due to the widespread perception of a healthy lifestyle. In the practice of developed foreign countries, a tendency has been established: an increase in the quality of life and the state of health of the population correspond to the average growth rate of traffic by bicycle transport, while exceeding the growth rate of traffic in other modes of transport. It should be noted that not always in Russian cities, the transport infrastructure can be transformed in order to create bike paths. For example, even at the existing road junctions that have been put into operation, there are no paths for pedestrians and cyclists to pass. We carried out a study on the example of a large city in the Russian Federation, where traffic interchanges are designed to minimize traffic intersections and increase throughput. However, the authorities, deciding the issue of increasing traffic capacity, forget about the comfortable movement of pedestrians and cyclists. To create such conditions, we propose to develop a project for a pedestrian-bicycle bridge in the formed transport infrastructure, which is provided only for road transport [1-6].

\section{Analysis of the research problem}

Russian cities are developing rapidly, social and economic conditions are changing, the city is expanding, its border is increasing, new free territories are being built up, along with these, the transport infrastructure is developing. The transport infrastructure of a large city is a transport "artery" along which traffic flows smoothly, provides convenient and shortest connections of all city districts with each other and with external communication routes. Currently, a systematic approach to the development of urban transport networks is advisable in terms of linking the movement of all types of transport, as well as walking and cycling routes. In the course of the functioning and development of transport interchanges of the city, problems arise with the movement of pedestrians and cyclists along such transport arteries, since state authorities prioritize the convenience of movement for road transport and do not consider the issues of pedestrian movement, let alone bicycle transport. This situation occurs in almost every major city in Russia. We have studied the scientific works of Russian and foreign scientists who are dealing with issues in this area. Consider this problem on the example of a large city.

In 2010, in the city of Tyumen, the largest and most complex traffic intersection was put into operation. Interchange on the street Maurice-Toreza is a very important junction in the city's transport system, its construction has significantly improved road traffic in this area, see Fig. 1 [7-10]. 


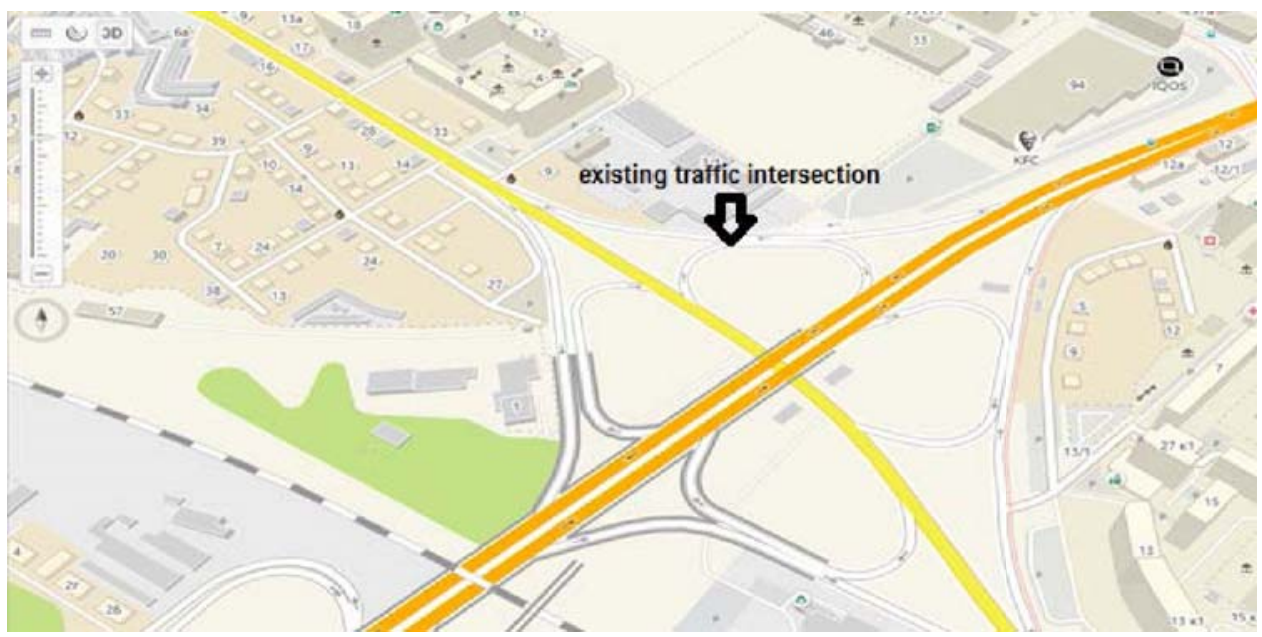

Fig. 1. Existing transport interchange.

Due to the complex system of congresses and arrivals, it is impossible to provide pedestrian sidewalks along the road at the junction, as is usually designed on overpasses. To solve this problem, the pedestrian path is laid at ground level in the direction from northwest to southeast, parallel to the overpass.

The pedestrian path crosses highways and the Trans-Siberian Railway. To overcome this junction on foot, you need to go through three underpasses, one tunnel and one covered overpass over the railroad tracks [6, 11-13].

The total length of the path is 600 meters. There are practically no residential buildings and social and cultural facilities along the pedestrian path. Moving along the pedestrian path, a person finds himself in a quiet, deserted space, which resembles an obstacle course. At any time of the day, people are not here or almost not. (fig. 2,3,4).

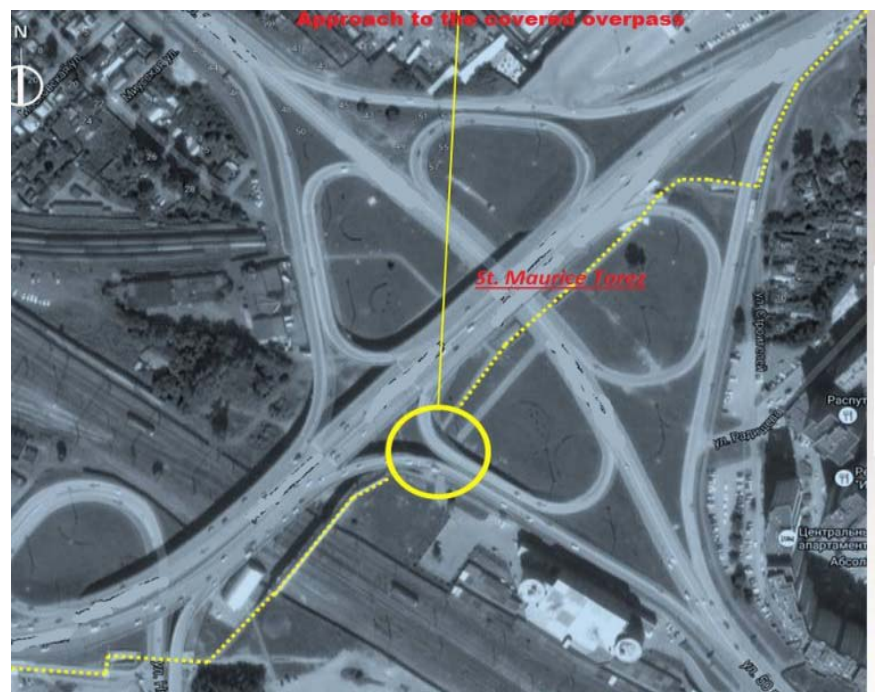

"New Park" (project)

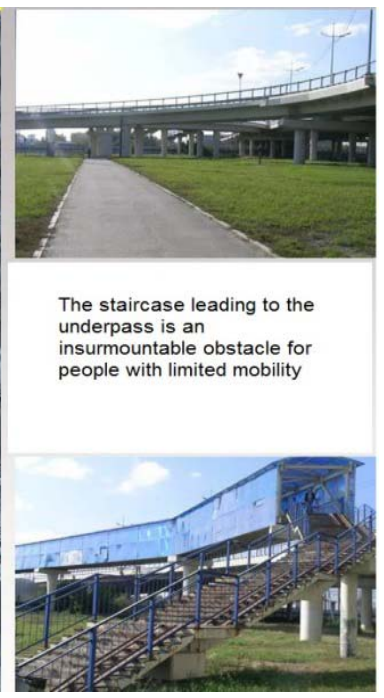

The staircase leading to the underpass is an

insurmountable obstacle fo people with limited mobility

Fig. 2. Approach to the covered overpass. 


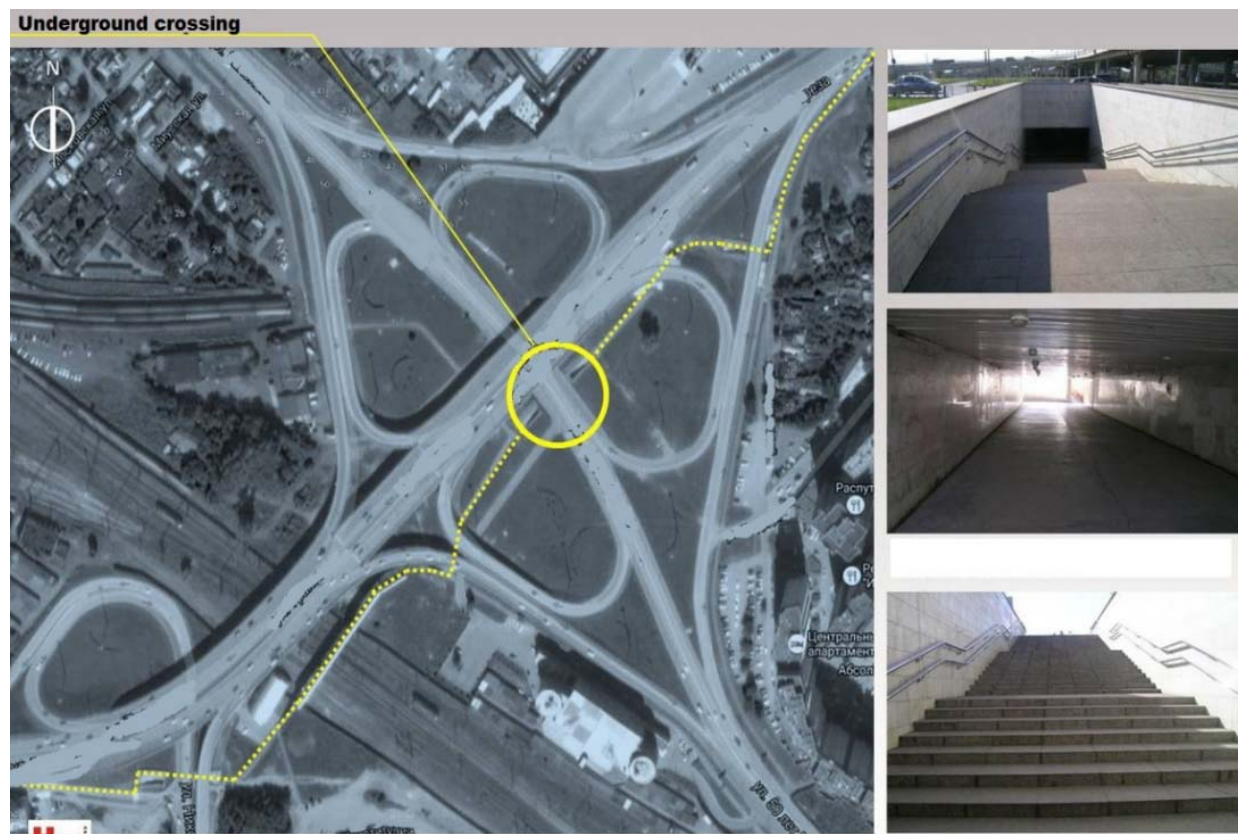

Fig. 3. Underground crossing.

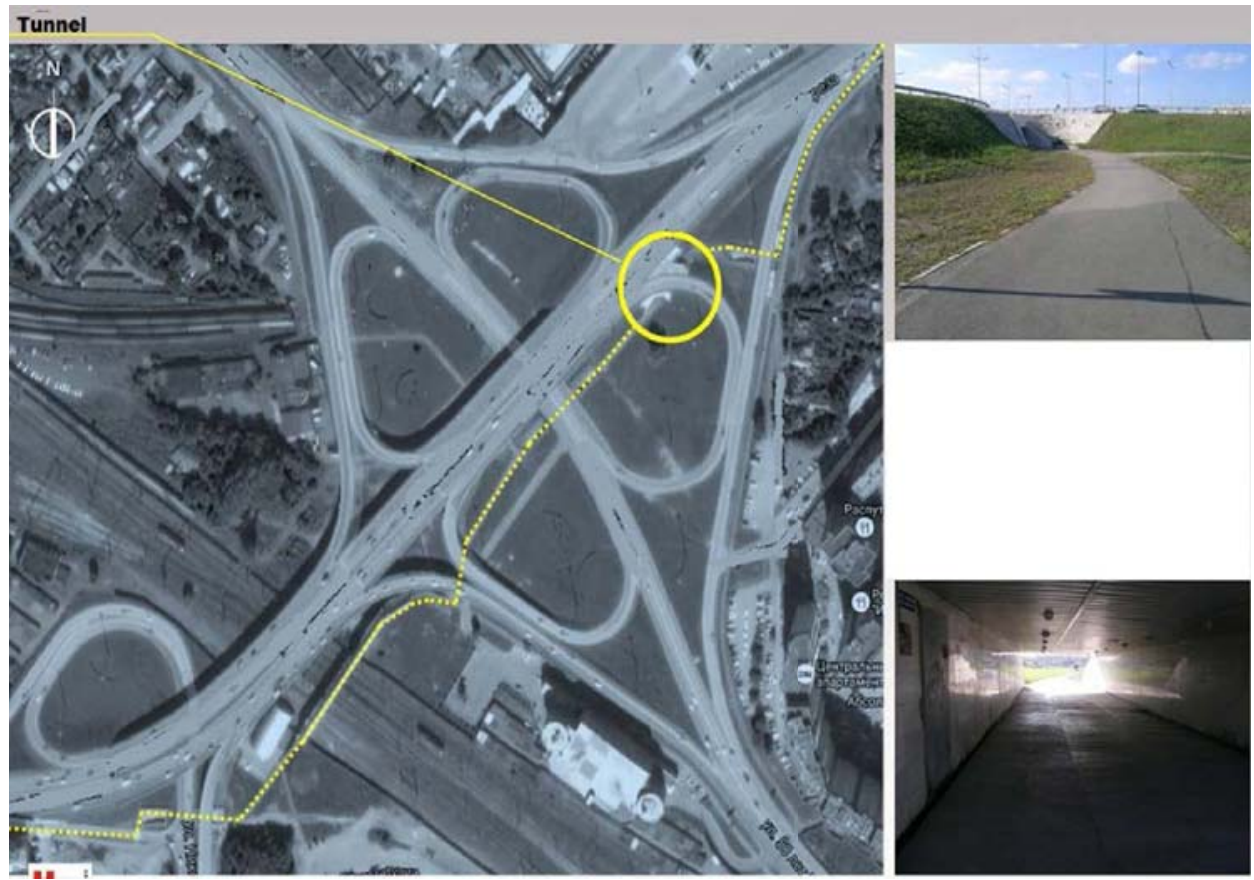

Fig. 4. Tunnel.

People avoid this place. Many townspeople have no idea at all how it is possible to cross this junction otherwise, except by car. The city authorities, solving the transport problem, created a problem for pedestrians (it should be noted that this situation is not the only one in the city). 


\section{Analysis of foreign experience}

To develop proposals on the existing problem, namely on the creation of a movement zone for pedestrians and cyclists, it is necessary to consider the experience of projects in foreign countries. We studied several projects that helped in the design and decision-making for the creation of a pedestrian and bicycle green bridge in the city.

For example, the London government has launched a program to create a system for the safe movement of cyclists. As part of this program, Foster Partners and Space Syntax decided to create real bicycle highways over existing highways and railways. The SkyCycle project involves the construction of such "heavenly" bike paths with a total length of 220 $\mathrm{km}$, that is, almost over all the highways of the English capital (Fig. 5).

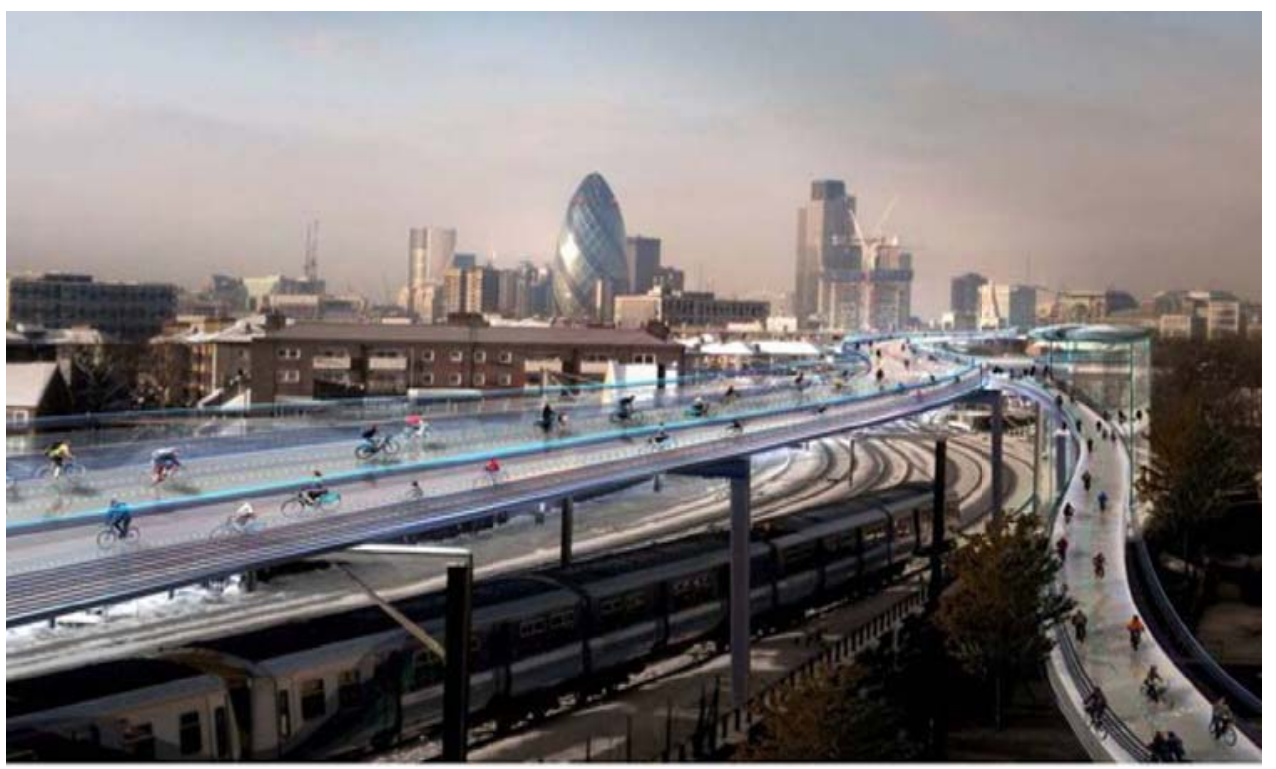

Fig. 5. The SkyCycle project ( https://sajjadi.livejournal.com/395606.html).

The Danish authorities are known to pay particular attention to the development of infrastructure for cyclists. One of the most famous recent projects in this area is the Copenhagen bicycle bridge, designed by the DASSING + WEITLING Architecture. The presence of such a bridge solved logical problems in a part of the city:

- provided bicycle owners with a convenient ride through the territory

- saved the surrounding area from excessive bicycle traffic, providing a free area for pedestrians (Fig. 6)

Due to its winding shape, the bridge was named Bicycle Snake. It is a metal structure with a bright orange road surface and backlighting, making it easy for cyclists to identify the direction of travel, even at night. 


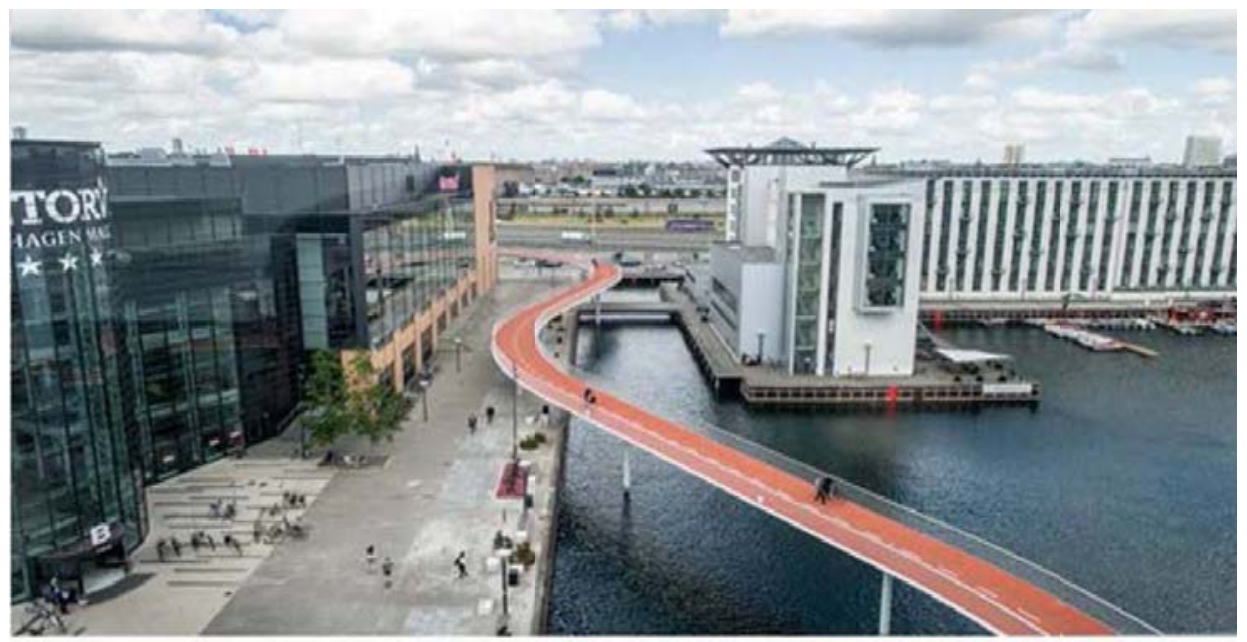

Fig. 6. Bicycle Snake, Danish (https://rus.architecturaldesignschool.com/lego-house-bicycle-snakehonored-2018-danish-design-awards-36537).

A two-level pedestrian bridge (Nature Bridge) in Tehran will connect two large parks, separated by highways. Each park has a well-thought-out set of paths leading to the bridge. It not only allows you to get from point A to point B, there are benches, green areas inside, and on the lower level there are two restaurants, on both ends of the bridge. Different levels of the bridge are connected by ladders and passages. The unusual shape allows you to change the view with each step. (fig. 7).

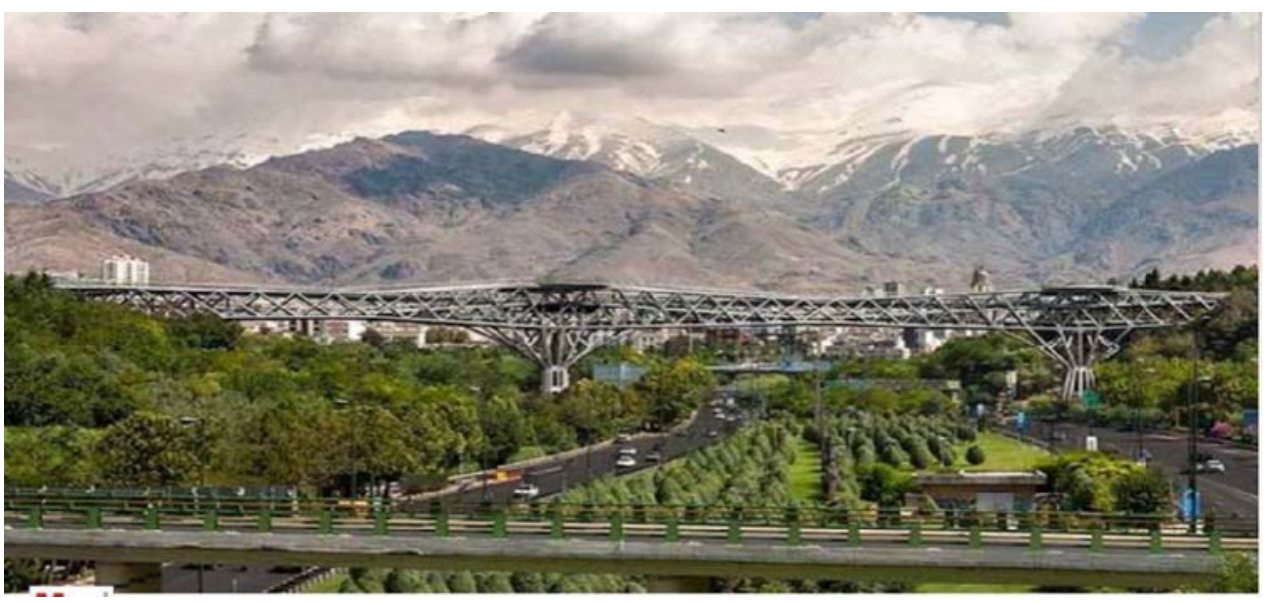

Fig. 7. Nature Bridge in Tehran (https://sajjadi.livejournal.com/395606.html).

The Arganzuela Pedestrian and Bicycle Bridge in Madrid is a unique and most beautiful bridge in two parts, 150 and 128 meters. The bridge is divided into two parts: pedestrian and bicycle, between them there are wooden benches for rest. The cone-shaped pipes are united in the central part with each other on a small hill, which is also an observation deck. (fig. 8) 


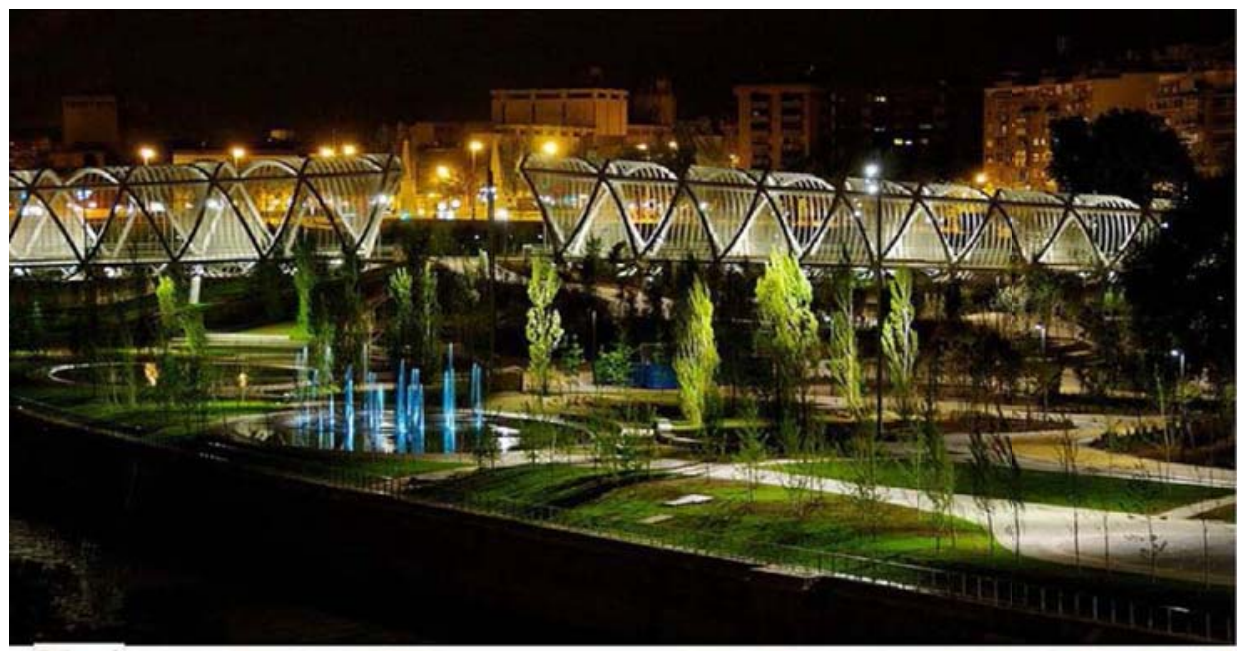

Fig. 8. The Arganzuela Pedestrian and Bicycle Bridge in Madrid (http://www.mirkrasiv.ru/articles/most-truba-argansuyela-v-madride-ispanija.html).

The presented projects serve to maintain the quality of the urban living environment of the population and environmental protection. Such structures can be located both around cities and within them [14-18].

\section{Developed proposals}

We propose to create a unique public space, a green pedestrian and bicycle bridge connecting urban areas. The total length of the bridge from the starting point in the Zheleznodorozhnikov public garden to the Voyage Gallery shopping center is 820 meters. With a width of 15 meters, the bridge has a five-part division: three "green lanes", a pedestrian path and a bicycle path. The cycle path is two-lane, 3.5 meters wide, the pedestrian lane is 6.8 meters wide. The width of the pedestrian path allows people of all ages and varying degrees of activity to move safely along it: walking, running, etc. Rain and melt water from the bridge can be collected in reservoirs located on both sides at the base of the bridge. In summer, this water can be used in an irrigation system, eliminating the use of water from city networks. The Green Bridge is a barrier-free space. The slope on the rise is 1:20, which allows people with disabilities of all categories (people with limited mobility) to move along it:

- elderly people;

- parents with baby carriages;

- disabled people in wheelchairs;

- temporarily injured people.

The cycle and footpaths are separated by a cotoneaster hedge. The pedestrian part of the bridge is separated from the edge by a strip of greenery - perennials 2.5 meters wide with "islands" for rest. Resting places are equipped with benches, urns, compositions of shrubs, stones and flowers are visually distinguished. It is possible to install kiosks for the sale of coffee, pastries, ice cream, newspapers, closed booths for ATMs and vending machines.

The bicycle part of the bridge is separated from the edge by a green strip 1.5 meters wide, on which small conifers (thuja, juniper) are planted in order to create a favorable ecological environment and to protect the prevailing north-westerly winds. The Green Bridge provides a convenient pedestrian connection between the city center and Komsomolsky Park, which is popular with city residents and visitors, see Fig.9. 


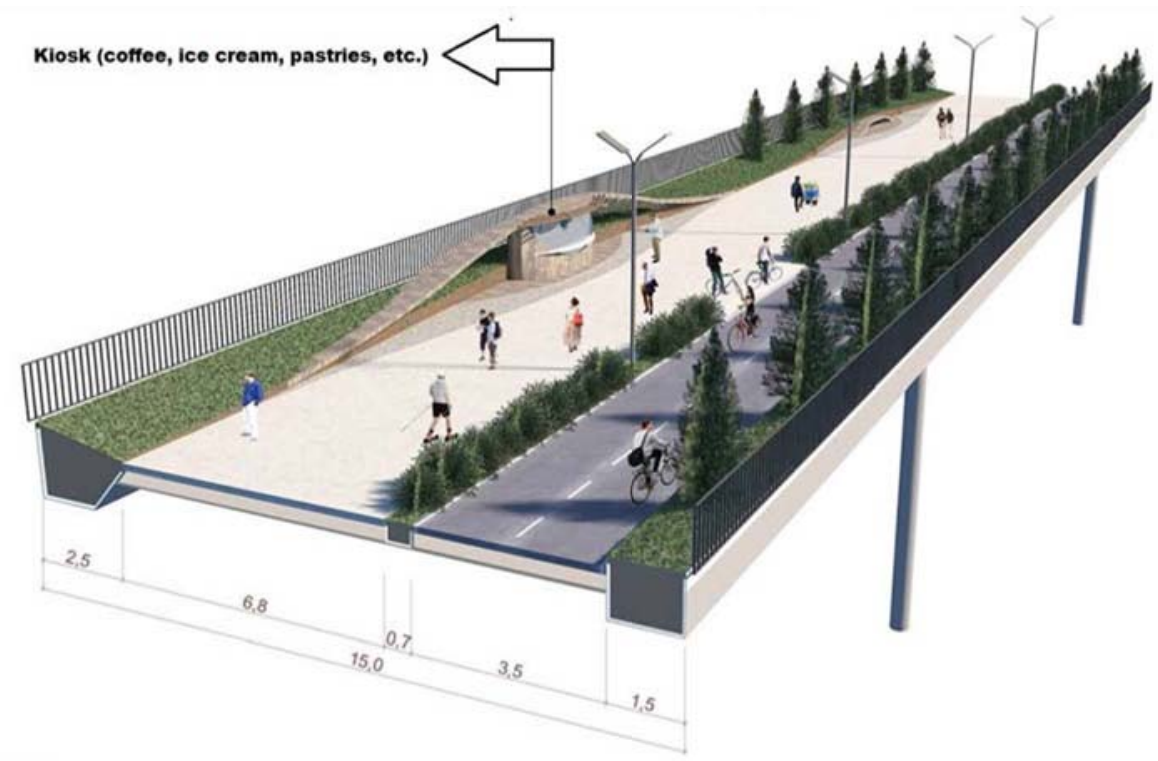

Fig. 9. Project proposal for the development of pedestrian and bicycle paths.

There is a closed area of the pre-trial detention center near the Green Bridge, in the approved city development strategy this institution is planned to be moved to another location, then a New Park can be designed and created on the vacated site.

The city youth center can become the compositional dominant of the New Park. (fig 10, $11)$.

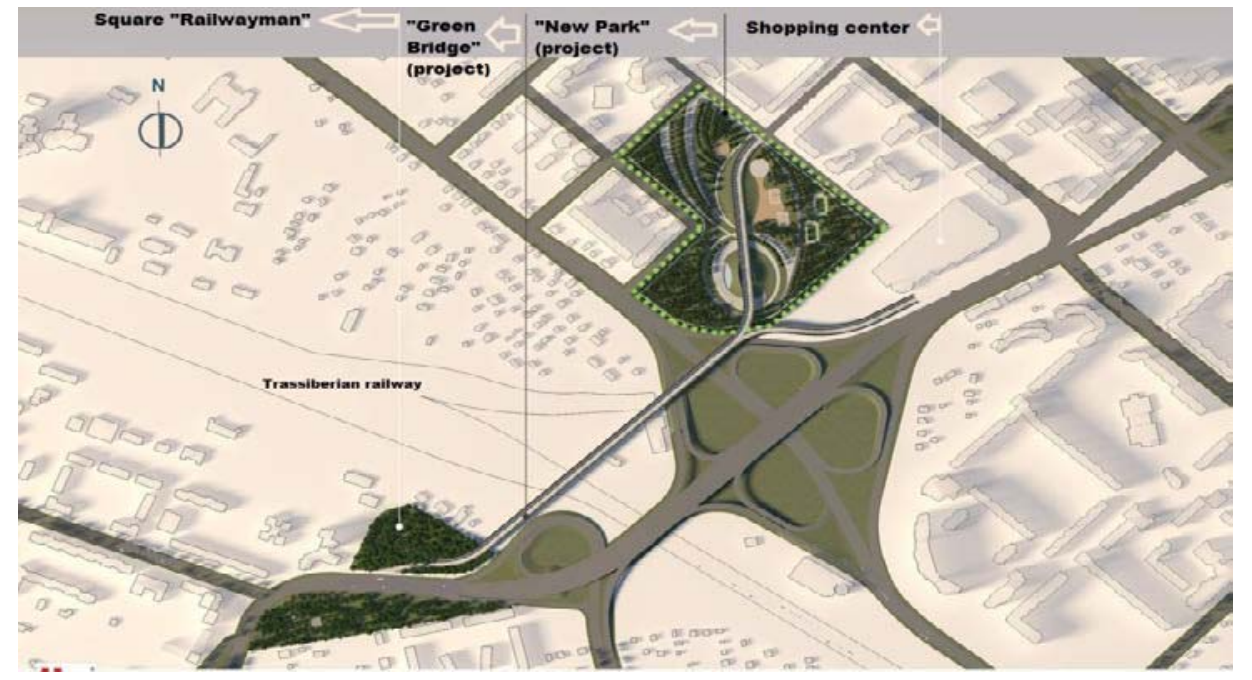

Fig. 10. Territory development prospects. 


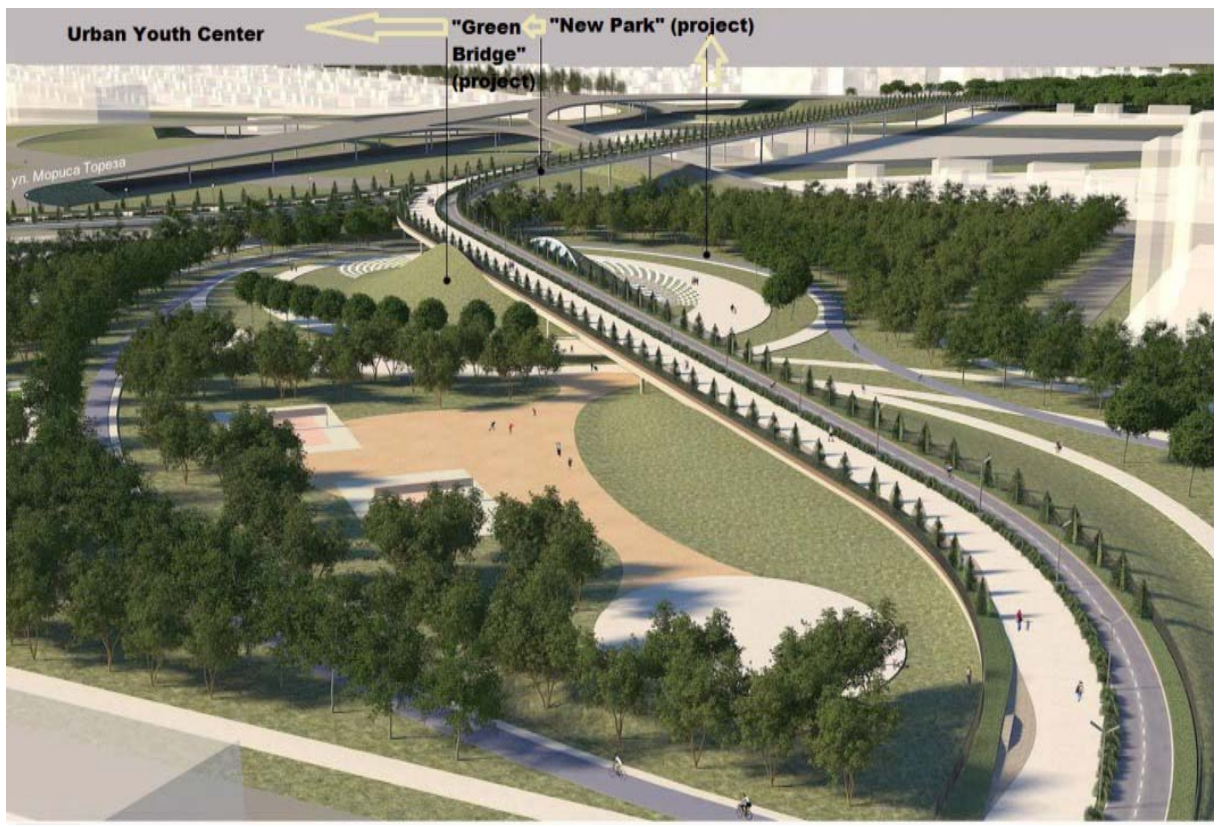

Fig. 11. Territory development prospects.

Then the "Green Bridge" will be an excellent link that will unite urban public spaces into a single system.

The estimated cost of construction and installation work of the Green Bridge is about $1,230,000$ euros. (prices in 2018). The project cost was calculated based on the following indicators:

- building area - $12,430 \mathrm{~m} 2$

- landscaping area - $3290 \mathrm{~m} 2$

- area of hard coverings - $9140 \mathrm{~m} 2$ of which:

a) bike paths $-3300 \mathrm{~m} 2$

b) sidewalk - $5840 \mathrm{~m} 2$

- construction volume - $19000 \mathrm{~m}^{3}$

\section{Conclusion}

The practical significance of the study lies in the development of recommendations for the modernization of the city's transport infrastructure. The developed project for the creation of pedestrian and bicycle paths "Green Bridge" can be used by federal and regional government bodies when analyzing the effectiveness of changes in the level of development of transport infrastructure.

An analysis of the existing transport infrastructure of a large city showed the need to develop such projects in order to create comfortable conditions for the movement of pedestrians and bicycle transport. The named prospects for the development of the transport framework create the prerequisites for qualitatively new ideas for the development of the territory.

Subject to the development of a new transport and logistics system in the city, it is possible to create attractive routes for tourists, reduce the time spent on cycling, and create comfortable zones for pedestrians. There is no single algorithm, that is, there is no formula 
for calculating comfort, but we can develop and implement urban infrastructure facilities to create comfortable conditions for staying and moving around the city.

In modern conditions, it is necessary to create an effective mechanism for managing the transport infrastructure, which will be modernized or transformed with the development of the scientific and technical process. In the future, the transport infrastructure of Russia will have to transform the appearance of the city by installing additional pedestrian and bicycle transport routes, both ground and overhead.

\section{Acknowledgements}

The authors express their gratitude to the Department of Urban Development and Land Relations of the city of Tyumen for the provision of urban planning documentation, as well as the administration of the city of Tyumen, the department of forecasting and planning of city infrastructure

\section{References}

1. Y. Alekseev, Elevated highways over the railway. Development and Reconstruction of the Social and Transport Infrastructure of the Metropolis (Association of Construction Universities (ASV), Moscow, 2016)

2. ArchitecturalDesingSchool.com

(Denmark), https://rus.architecturaldesignschool.com/lego-house-bicycle-snake-honored-2018danish-design-awards-36537

3. O. Bely, O. Kokaev, S. Popov, Architecture and methodology of transport systems: monograph (2018)

4. G. Velichko, Science and technology in the road industry 3(50), 19-22 (2009)

5. Y. Golskaya, The influence of transport infrastructure on the development of the region (LAP Lambert Academic Publishing, 2018)

6. General plan of the city of Tyumen (2017) http://www.tyumencity.ru/vlast/administration/struktura-administracii-goroda-

tumeni/departaments/dzr/napravlenie-

deitelynosti/departamentgradostroitelynoipolitiki/genplan/

7. N. Maslov, Urban planning ecology: Textbook. manual for students studying in the specialty "Urban construction and economy (2002)

8. Predictive social design: theoretical, methodological and methodological problems (Nauka, Moscow, 1994)

9. N. Reimers, Forecasting and social design. Theoretical, methodological and methodological problems 294 (1994)

10. T. Matsunuma, A. Koichi, Y. Naito, J. Tanaka, H. Goto, Civil Engineering Society, 51th Civil Engineering Studies Research / Lecture Collection (2015)

11. The concept of development of cycling in Russia https://velotransunion.ru/node/17

12. Livejournal. Pedestrian bridge, https://sajjadi.livejournal.com/395606.html

13. I. Morozova, Modernization of the transport infrastructure of Russia (LAP Lambert Academic Publishing, 2018)

14. Micro-scale sustainability assessment of infrastructure projects on urban transportation systems: Case study of Azadi district, Isfahan, Iran. Cities 72, 149-159 (2010) 
15. S. Ozun, Transport of Russia 10 (2008)

16. London Cycle Trail Project, https://sporter.md/ru/posts/velosport/potryasayuschijproekt-nebesnih-velotrass-v-londone-foto

17. K. Sekretev, New transport technologies 176 (2006)

18. Scheme of territorial planning of the transport infrastructure of the city of Tyumen (2018)

https://fgistp.economy.gov.ru/?show_document=true\&doc_type=npa\&uin=717010000 2010320180131247

19. Travel portal "The world is beautiful", http://www.mirkrasiv.ru/articles/most-trubaargansuyela-v-madride-ispanija.html 